\title{
Changes in neutrophil motility accompanying dapsone and rifampicin therapy
}

\author{
R ANDERSON* \& EMS GATNER ${ }^{\dagger}$ \\ *Immunology Section, \\ Department of Medical Microbiology, \\ Institute of Pathology, University of Pretoria, and \\ ${ }^{\dagger}$ The Tuberculosis Research Institute of the \\ South African Medical Research Council, \\ Private Bag X385, Pretoria
}

Received for publication 24 November 1980

Summary Dapsone has been shown to stimulate the motility of normal neutrophils in vitro and the neutrophils of patients with lepromatous and tuberculoid leprosy in vivo. It is suggested that dapsone possesses immunostimulatory activity.

\section{Introduction}

We have previously reported that dapsone therapy in patients with lepromatous leprosy was associated with progressive improvement of neutrophil migration and mitogen-induced lymphocyte proliferation (Anderson, Gatner, Imkamp \& Kok, 1980). ${ }^{1}$ These observations could have been due to a primary immunopharmacological action of the drug or alternatively to a secondary phenomenon due to the antimicrobial activity of the drug (as a result of decreased levels of bacteria-derived serum inhibitors of leucocyte functions). We have now investigated the in vitro effects of dapsone on the motility of normal neutrophils and the in vivo effects in patients with tuberculoid leprosy receiving dapsone only and rifampicin or dapsone only in a group of patients with lepromatous leprosy.

\section{Patients and methods}

\section{PATIENTS}

Twenty-four new untreated admissions $(6 \mathrm{LL}, 6 \mathrm{BL}, 8 \mathrm{BT}$ and 4BB) were classified according to the clinical and histopathological criteria of Ridley and 
Jopling (1966). ${ }^{2}$ The $6 \mathrm{LL}$ and $6 \mathrm{BL}$ patients comprised the lepromatous leprosy group and the $8 \mathrm{BT}$ and $4 \mathrm{BB}$ patients formed the tuberculoid leprosy group.

\section{EXPERIMENTAL PROTOCOL}

Patients in the lepromatous leprosy group received dapsone only (DDS, $100 \mathrm{mg}$ daily) for the first week of therapy after which therapy with rifampicin only for 6 weeks ( $600 \mathrm{mg}$ daily) was commenced. Testing of neutrophil motility was performed prior to dapsone therapy, $2 \mathrm{~h}$ after the ingestion of a single $100 \mathrm{mg}$ oral dose (to investigate possible immunopharmacological effects) and one week after the ingestion of $100 \mathrm{mg}$ dapsone daily; testing was also performed after the 6-week period of rifampicin therapy. In patients with tuberculoid leprosy neutrophil motility was tested prior to dapsone therapy and 4 weeks after therapy with $100 \mathrm{mg}$ dapsone daily.

\section{STUDIES OF NEUTROPHIL MOTILITY}

Neutrophils were obtained from heparinized venous blood ( 5 units heparin $/ \mathrm{ml}$ ) processed as previously described (Anderson et al, 1980) ${ }^{1}$ and resuspended to a final concentration of $5 \times 10^{6} / \mathrm{ml}$. One leucoattractant was used, viz. endotoxin-activated autologous serum (EAS) prepared by activation of fresh serum with $100 \mu \mathrm{g} / \mathrm{ml}$ of bacterial endotoxin (E. coli: 0127: B8 Difco, Detroit, Michigan, USA). Neutrophil motility was assessed as previously described (Anderson and van Rensburg, 1979). ${ }^{3}$ Chambers were incubated and the results expressed as the average number of cells reaching the lower surface of the $5 \mu$-pore size Millipore filter after $3 \mathrm{~h}$ incubation and expressed as an average for triplicate filters.

Dapsone powder for in vitro experiments was obtained from Lennon Laboratories (Pty) Ltd, Port Elizabeth, South Africa, and dissolved in HBSS. The concentration range investigated was $10^{-6} \mathrm{M}-10^{-2} \mathrm{M}$. In these experiments to assess the effects of dapsone on the motility of neutrophils from normal adult volunteers to autologous EAS an incubation period of $2 \mathrm{~h}$ was used. Dapsone was present with the neutrophils in the upper compartment of the chemotaxis chamber throughout the incubation period.

\section{Results}

In vitro effects of dapsone

Results on the migration of normal neutrophils are shown in Table 1. Dapsone at concentrations of $>10^{-4} \mathrm{M}$ caused stimulation of motility which was statistically significant at concentrations of $10^{-3} \mathrm{M}, 2.5 \times 10^{-3} \mathrm{M}$ and $5 \times 10^{-3} \mathrm{M}$. 
Table 1. The effects of dapsone in vitro on the migration of normal neutrophils to autologous EAS

\begin{tabular}{lcc}
\hline Dapsone concentration & Neutrophil migration to EAS & Pvalue* $^{*}$ \\
\hline Control & $169 \pm 18^{\dagger}$ & \\
$1 \times 10^{-3}$ Molar & $243+20$ & $<0.05$ \\
$2.5 \times 10^{-3}$ Molar & $266 \pm 21$ & $<0.05$ \\
$5 \times 10^{-3}$ Molar & $259 \pm 22$ & $<0.05$ \\
\hline
\end{tabular}

*Statistical analysis was performed by the Student's $t$ test for paired means.

$\dagger$ Results as the mean value in cells/microscope high power field for six different individuals

\section{In vivo effects of dapsone and rifampicin}

Results in patients with lepromatous leprosy are shown in Table 2. Dapsone therapy was associated with significantly improved neutrophil motility to autologous EAS. Rifampicin therapy was associated with a slight decrease in neutrophil motility (Table 2).

Table 2. Effects of dapsone only and rifampicin only on neutrophil migration to autologous EAS in patients with lepromatous leprosy

\begin{tabular}{|c|c|c|c|}
\hline \multicolumn{4}{|c|}{ Neutrophil migration to EAS } \\
\hline Pre-therapy & $\begin{array}{c}2 \mathrm{~h} \text { after } \\
\text { ingestion of } \\
100 \mathrm{mg} \text { dapsone }\end{array}$ & $\begin{array}{c}\text { After } 1 \text { week } \\
100 \text { mg dapsone } \\
\text { daily }\end{array}$ & $\begin{array}{l}\text { After } 6 \text { weeks' } \\
\text { therapy with } \\
\text { rif ampicin only } \\
\text { (600 mg daily) }\end{array}$ \\
\hline $28.5 \pm 12.6^{*}$ & $\begin{array}{l}57.4 \pm 28.4 \\
(<0.05)^{\ddagger}\end{array}$ & $\begin{array}{l}75.3 \pm 20.4^{\dagger} \\
(<0.05)\end{array}$ & $44.8 \pm 15.9$ \\
\hline
\end{tabular}

${ }^{*}$ Results as the mean value with standard error as cells/high power field.

$\dagger^{\dagger}$ Dapsone therapy stopped at this stage prior to commencement of rifampicine therapy.

‡ value calculated by the Wilcoxon Signed-Rank test.

In vivo effects of dapsone therapy

Results in patients with tuberculoid leprosy are shown in Table 3. Ingestion of dapsone caused a significant increase of neutrophil motility.

Table 3. Effects of Dapsone only on neutrophil migration to EAS in patients with tuberculoid leprosy

\begin{tabular}{|c|c|}
\hline \multicolumn{2}{|c|}{ Neutrophil migration to EAS } \\
\hline Prior to dapsone therapy & 4 weeks after ingestion of $100 \mathrm{mg}$ dapsone daily \\
\hline $109.2 \pm 23.4^{*}$ & $\begin{array}{c}200.0 \pm 38.1 \\
(<0.05)^{\dagger}\end{array}$ \\
\hline
\end{tabular}

${ }^{*}$ Results as mean cells/microscope high power field with standard error.

$\dagger P$ value calculated by the Wilcoxon Signed-Rank test. 


\section{Discussion}

In this study dapsone at concentrations of $>10^{-4} \mathrm{M}$ has been shown to stimulate neutrophil motility in vitro. These findings suggest that in vivo stimulation of leucocyte migration would require serum levels of dapsone of $>25 \mu \mathrm{g} / \mathrm{ml}$ which indicates that dapsone stimulation would not be achieved following ingestion of $100 \mathrm{mg}$ of dapsone. However we have previously reported for levamisole that concentrations of this agent required to stimulate neutrophil motility in vivo are considerably less than those required in vitro (Anderson, Oosthuizen, Theron \& van Rensburg, 1979). ${ }^{4}$

In order to investigate the immunopharmacological activity of dapsone the effects of the drug on neutrophil motility were studied prior to and $2 \mathrm{~h}$ after the ingestion of a single $100 \mathrm{mg}$ oral dose. Significant stimulation of neutrophil migration was observed which justifies our previous suggestion (Anderson et al. 1980) ${ }^{1}$ that dapsone may possess immunostimulatory activity. It was not established if the dapsone-mediated changes in motility were cell or serumrelated. Rifampicin therapy was associated with a slight decrease in neutrophil motility in vivo. Stendahl, Molin and Dahlgren $(1970)^{5}$ have reported that dapsone in vitro had no effects on PMN migration to zymosan-activited serum which is not in agreement with this report. These differences are probably related to the low concentrations of dapsone investigated by Stendahl et al. ${ }^{5}$

These findings show that dapsone in addition to antimicrobial and suspected anti-inflammatory activity (Thomson and Souhami, 1975) ${ }^{6}$ possesses immunostimulatory properties. There is the suggestion that dapsone therapy may be involved in the pathogenesis of erythema nodosum leprosum (ENL) since dapsone causes increased migration of neutrophils and may therefore also increase the locomotion of mononuclear cells and macrophages. Further studies are in progress to investigate the mechanism of dapsone-mediated stimulation of neutrophil motility.

\section{References}

1 Anderson R, Gatner EMS, Imkamp FMJH, Kok SR. In vivo effects of propranolol on some cellular and humoral immune functions in a group of patients with lepromatous leprosy. Lepr Rev, 1980 51, 137.

2 Ridley DS, Jopling WH. Classification of leprosy according to immunity. Int J Lepr, 1966 $34,255$.

3 Anderson R, van Rensburg AJ. The in vitro effects of propranolol and atenolol on neutrophil motility and post-phagocy tic metabolic activity. Immunology, 1979, 37, 15.

4 Anderson R, Oosthuizen R, Theron A, van Rensburg AJ. The in vitro evaluation of certain neutrophil and lymphocyte functions following the ingestion of a $150 \mathrm{mg}$ oral dose of levamisole: assessment of the extent and duration of stimulation of neutrophil chemotaxis, protein iodination and lymphocyte transformation. Clin Exp Imm, 1979, 35,478 .

5 Stendahl O, Molin L, Dahlgren C. The inhibition of polym-phonuclear leukocyte cytotoxicity by dapsone. J Clin Invest, 1970, 62, 214.

6 Thomson DM, Souhami R. Suppression of the Arthus reaction in the guinea-pig by dapsone. Proc R Soc Med, 1975, 68, 273. 